\title{
Olhares sobre a hidreletricidade e o processo de licenciamento no Brasil
}

\author{
Priscilla MELLEIRO PIAGENTINI, ${ }^{\mathrm{I}}$ \\ ROSELI FREDERIGI BENASSI II \\ e ClÁUdio Luis CAMARGO PENTEADO ${ }^{I I I}$
}

\section{Introdução}

A HIDRELETRICIDADE é uma alternativa energética que tem um papel destacado no cenário elétrico mundial em virtude de seus benefícios, entre eles, seu caráter renovável e pouco poluente. No Brasil, por exemplo, responde pelo suprimento de mais de $80 \%$ da demanda por energia elétrica.

A instalação de usinas hidrelétricas (UHE) envolve uma série de atores, com diversos interesses, frequentemente antagônicos, o que se reflete na complexidade e recorrência de cenários conflituosos. Hidrelétricas podem interferir positiva ou negativamente na dinâmica local, provocando conflitos que podem ser tanto mais graves e de difícil equacionamento quanto mais discrepantes forem os interesses em causa, o que resulta dos diferentes usos e significados dos recursos naturais e do espaço geográfico para cada grupo envolvido e, mais do que isso, das formas adotadas por esses, para atingir os seus objetivos.

Para Brito et al. (2011), os conflitos socioambientais tornaram-se frequentes depois da criação do Clube de Roma (1968) e da Conferência de Estocolmo (1972). No Brasil, os conflitos envolvendo a instalação de UHE ficaram mais evidentes com o fortalecimento da legislação ambiental, a partir da década de 1980 (Alonso; Costa, 2002; Acselrad, 2004; Vainer, 2007), especialmente, com a definição da política ambiental brasileira (Lei Federal n.6.938/1981) e das resoluções do Conama atinentes ao processo de licenciamento e à Avaliação de Impactos Ambientais (AIA) mediante a elaboração de Estudos de Impacto Ambiental (EIA-Rima), que permitiram a ampliação do debate. Tais normas trouxeram consigo a possibilidade de participação da sociedade civil em consultas e audiências públicas.

No licenciamento ambiental brasileiro, cabe às esferas governamentais decidir sobre a viabilidade de um empreendimento. Essa situação dificulta o cumprimento do papel de mediador que se espera do governo durante o processo de discussão sobre a instalação de um determinado empreendimento. O que se observa é tão somente a identificação de medidas que possam minimizar as 
preocupações ambientais de um dado projeto (Agra Filho, 2008). O papel exercido pelos órgãos governamentais não é o esperado quando se trata de gestão dos conflitos.

Brito et al. (2011) estudaram os conflitos socioambientais no Brasil e no mundo e constataram que esses surgem em razão da superposição de usos e percepções diferentes, inclusive antagônicas, de um espaço geográfico ou recurso natural. Os conflitos também podem ser desencadeados pelo desequilíbrio entre exploração e reposição dos recursos naturais, traduzindo-se em escassez; o uso propriamente dito de recursos naturais e a incompatibilidade de interesses sobre o uso desses num determinado espaço geográfico. No Brasil, tais conflitos ocorrem em virtude da disputa pela apropriação do patrimônio natural.

Os conflitos podem ser positivos, prevenindo a estagnação de uma relação, estimulando a curiosidade e criando novos interesses, além de permitirem explorar a capacidade de cada indivíduo (Deutsch, 2003). Segundo Pimentel (2012), o conflito é positivo se a estrutura político-cultural da região, o arranjo institucional e o envolvimento público, facilitar a sua gestão. Nessa óptica, a correta administração dos conflitos auxilia o processo decisório, por fortalecer a integração social e aumentar a eficiência e a flexibilidade das ações governamentais (Swain; Chee, 2004). Entretanto, quando mal geridos, os conflitos podem ser negativos, por se transformarem em cenários de confrontos que dificultam o processo para todos os envolvidos.

Este artigo apresenta os resultados obtidos da resposta a questionários sobre a hidreletricidade e o processo de licenciamento ambiental de usinas hidrelétricas. A pesquisa abrangeu segmentos distintos da sociedade e, portanto, a representatividade das informações é bem diversificada, o que permitiu conduzir uma análise das questões envolvendo a hidreletricidade e o processo de licenciamento ambiental.

\section{Atores envolvidos}

Geralmente, os atores sociais participantes do processo de licenciamento ambiental de UHE costumam ser divididos em dois grandes grupos: os favoráveis e os desfavoráveis. O grupo dos favoráveis, normalmente, vê vantagens na instalação de usinas hidrelétricas quer pela geração de energia para a sociedade como um todo, quer para algum setor específico; pela possibilidade de desenvolvimento local e regional e, ainda, pelas possibilidades de crescimento das atividades que direta ou indiretamente estão associadas à instalação de grandes barragens.

Normalmente, os atores favoráveis são representados por órgãos do governo, em todas as suas esferas - federal, estadual e municipal - e por grupos empresariais, públicos e privados, interessados nos produtos advindos da geração hidrelétrica. Em analogia à sustentabilidade, tendo como cenário o modelo econômico atualmente vigente no Brasil, os interesses dos "favoráveis" se fundamentam na necessidade de crescimento econômico e veem a sustentabi- 
lidade estampada na possibilidade de minimização e compensação de impactos ambientais. Nessa óptica, o grupo dos "favoráveis" tem, de certo modo, seus interesses sobrepostos aos demais, tornando-os, muitas vezes, autoritários e centralizadores em suas tomadas de decisão (Galvanese, 2009).

O grupo dos "desfavoráveis" é constituído, basicamente, por organizações civis, movimentos sociais, organizações não governamentais (ONG) e outros grupos representantes da sociedade, especialmente da parte diretamente atingida pelo empreendimento. Segundo Galvanese (2009), "os desfavoráveis" ou menos favorecidos defendem a equidade entre os pilares reivindicando a importância da inserção equânime das questões socioambientais no processo de licenciamento ambiental.

\section{Interesses versus interpretações}

A percepção dos atores envolvidos sobre hidreletricidade e o processo de licenciamento ambiental é influenciada, entre outras razões, pelos interesses de cada grupo social. Isso não quer dizer que indivíduos de um mesmo grupo compartilhem sempre as mesmas opiniões, mas, de modo geral, suas ações se respaldam nos interesses e nos objetivos que precisam ser atingidos. Nesse sentido, considerou-se fundamental conhecer a opinião dos atores envolvidos nos temas tratados nessa pesquisa. O questionário aplicado foi estruturado por questões dissertativas, envolvendo onze eixos temáticos:

- Razões para a ocorrência de conflitos;

- Caráter limpo, renovável e sustentável;

- Itens imprescindíveis no licenciamento;

- Impactos positivos da hidreletricidade;

- Impactos negativos da hidreletricidade;

- Participação pública;

- Aspectos positivos do licenciamento;

- Lacunas do licenciamento;

- O licenciamento hoje;

- O setor elétrico e a sustentabilidade; e,

- Desafios futuros.

Os participantes foram escolhidos de forma aleatória, considerando as instituições que atuam no licenciamento de usinas hidrelétricas e as possibilidades de participação de cada uma delas. Foram consideradas instituições-chave no processo: (i) órgãos públicos governamentais em todas as suas esferas de atuação; (ii) instituições de ensino e pesquisa e estudantes; (iii) concessionárias de energia elétrica, públicas ou privadas; (iv) empresas de consultoria que elaboram estudos ambientais; (v) instituições judiciais; (vi) organizações não governamentais $(\mathrm{ONG})$; e (vii) sociedade civil através de Movimentos e Associações. 
Foram contatadas 36 instituições para participar da aplicação do questionário. Dessas, 22 participaram. Os questionários foram respondidos entre novembro de 2012 e fevereiro de 2013. Nenhum participante foi identificado na pesquisa. Para manter a confidencialidade, foram classificados em grupos, conforme a sua área de atuação. Assim, foram definidos sete grupos de atores que participaram da pesquisa. A Tabela 1 identifica os grupos definidos e o status de participação na pesquisa.

Tabela l - Grupo de atores contatados para preenchimento de questionário

\begin{tabular}{l|c|c}
\hline GRUPOS & PREENCHERAM & $\begin{array}{c}\text { NÃO } \\
\text { PREENCHERAM }\end{array}$ \\
\hline Acadêmicos/Especialistas & 3 & 1 \\
\hline ONG/Movimentos Sociais/Ativistas & 3 & 1 \\
\hline Advogados/Promotores de Justiça & 3 & 1 \\
\hline Consultorias que elaboram EIA-Rima & 1 & 3 \\
\hline Empreendedor/Concessionárias & 3 & 1 \\
\hline Biólogos & 2 & 3 \\
\hline Governo & 3 & 2 \\
\hline Órgãos licenciadores & 1 & 1 \\
\hline Órgãos do setor elétrico & $\mathbf{2 2}(\mathbf{5 4 , 5 \% )}$ & 0 \\
\hline Órgãos de infraestrutura & 1 & $\mathbf{1 4 5 , 5 \% )}$ \\
\hline Órgãos de financiamento & 1 & 1 \\
\hline Órgãos locais & 1 & 1 \\
\hline TOTAL & 3 & 1 \\
\hline
\end{tabular}

O grupo denominado "Governo" foi dividido em subgrupos conforme a área de atuação. No caso do subgrupo "Órgãos Licenciadores”, por exemplo, foram entrevistados atores que atuam direta ou indiretamente no licenciamento de usinas hidrelétricas. ${ }^{1}$

\section{Olhares sobre a hidreletricidade}

e o licenciamento ambiental no Brasil

O Quadro 1 apresenta uma síntese dos resultados obtidos com a aplicação do questionário para cada eixo temático trabalhado, expressando como aquele tema foi interpretado pelos entrevistados, classificados nos sete grupos 
de atores participantes do processo. O Quadro revela opiniões e interpretações convergentes e divergentes por parte dos grupos entrevistados, evidenciando que os interesses de cada um deles, de certa forma, influenciam em sua opinião. Por outro lado, a análise dos questionários permitiu identificar a ocorrência de opiniões divergentes dentro de um mesmo grupo, indicando que existem outros fatores que contribuem para a formação de opinião, além dos interesses envolvidos.

Segundo a maioria dos entrevistados, as razões para a ocorrência de conflitos esbarram principalmente na dimensão do empreendimento, na diversidade de atores envolvidos e na magnitude dos impactos, trazendo para o cenário um número significativo de interesses, vários deles antagônicos. A instalação de UHE requer a ocupação de extensos espaços geográficos que deixam de abrigar diversidade ambiental e social, o que se traduz em perdas ambientais e sociais. Essas perdas, se mal geridas, se manifestam através dos conflitos.

A hidreletricidade foi considerada fonte de energia renovável, segundo a maioria dos entrevistados. Como ressalvas, a possibilidade de diminuição do estoque em virtude do aumento da degradação dos corpos d'água e, com isso, a piora na qualidade das águas e a vida útil do empreendimento. A hidreletricidade também foi considerada fonte de energia limpa, segundo a maioria dos entrevistados, ao menos, quando seu uso foi comparado ao uso de fontes fósseis. Ainda assim, pelo fato de haver estudos que comprovam que as UHE emitem Gases de Efeito Estufa (GEE), em menor ou maior quantidade, a depender do local onde forem instaladas, para o grupo que representou as $\mathrm{ONG}$, movimentos sociais e ativistas, a hidreletricidade não é limpa.

A hidreletricidade foi considerada sustentável para parte dos entrevistados, a exemplo dos grupos aos quais pertenciam os advogados, promotores de justiça, concessionárias de energia elétrica e instituições governamentais em todas as esferas. Para os acadêmicos, o caráter sustentável da hidreletricidade depende dos critérios utilizados para a avaliação. Para os demais grupos, a hidreletricidade não é sustentável em face dos impactos de grande magnitude a ela associados.

Para os entrevistados, para ser efetivo, o licenciamento deve considerar a elaboração de estudos ambientais mais aprofundados, o que não quer dizer longos, mas que possam trazer as respostas necessárias para a análise de viabilidade ambiental. Devem embasar-se em Termos de Referência (TR) claros e específicos para a região em estudo, possibilitando um olhar mais atento para as necessidades das comunidades diretamente atingidas. Além disso, segundo os entrevistados, as Audiências Públicas devem ser reformuladas de modo a permitir uma participação mais equânime entre os envolvidos. Segundo parte dos entrevistados, a reforma política pode garantir que os interesses políticos não se sobreponham aos demais interesses. 
Quadro l - Síntese dos resultados obtidos com os questionários aplicados com os atores envolvidos no processo de licenciamento ambiental no Brasil

\begin{tabular}{|c|c|c|c|c|c|c|}
\hline GRUPOS & $\begin{array}{c}\text { RAZÕES } \\
\text { PARAA } \\
\text { OCOR- } \\
\text { RÊNCIA DE } \\
\text { CONFLITOS }\end{array}$ & $\begin{array}{l}\text { LIMPA, } \\
\text { RENO- } \\
\text { VÁVEL, } \\
\text { SUSTEN- } \\
\text { TÁVEL? }\end{array}$ & $\begin{array}{l}\text { ITENS IM- } \\
\text { PRES- } \\
\text { CINDÍVEIS } \\
\text { DO LICEN- } \\
\text { CIAMENTO }\end{array}$ & $\begin{array}{l}\text { IMPACTOS } \\
\text { POSITIVOS } \\
\text { DA HI- } \\
\text { DRELETRICI- } \\
\text { DADE }\end{array}$ & $\begin{array}{l}\text { IMPACTOS } \\
\text { NEGATIVOS } \\
\text { DA HI- } \\
\text { DRELETRICI- } \\
\text { DADE }\end{array}$ & $\begin{array}{l}\text { PARTICI- } \\
\text { PAÇÃO } \\
\text { PÚBLICA }\end{array}$ \\
\hline $\begin{array}{l}\text { Acadêmi- } \\
\text { cos/ } \\
\text { Especia- } \\
\text { listas }\end{array}$ & $\begin{array}{l}\text { Dimensão do } \\
\text { empreendi- } \\
\text { mento } \\
\text { Redução } \\
\text { de espaços } \\
\text { geográficos } \\
\text { Espaço para } \\
\text { mani- } \\
\text { festação } \\
\text { pública } \\
\text { Existência de } \\
\text { lobbies }\end{array}$ & $\begin{array}{l}\text { Renovável } \\
\text { Menos po- } \\
\text { luente } \\
\text { O caráter } \\
\text { sustentável } \\
\text { depende } \\
\text { dos critérios } \\
\text { adotados }\end{array}$ & $\begin{array}{l}\text { Definição do TR } \\
\text { até a operação } \\
\text { Aplicação de } \\
\text { melhores práti- } \\
\text { cas em AIA } \\
\text { Alternativas } \\
\text { locacionais e } \\
\text { tecnológicas } \\
\text { Discussão no } \\
\text { EIA sobre o uso } \\
\text { de outras fontes }\end{array}$ & $\begin{array}{l}\text { Geração de } \\
\text { energia } \\
\text { Geração de } \\
\text { renda } \\
\text { Aumento da } \\
\text { arrecadação } \\
\text { municipal } \\
\text { Evita emissão } \\
\text { de GEE } \\
\text { Serviços às } \\
\text { comunidades } \\
\text { Aumento do } \\
\text { valor dos } \\
\text { imóveis }\end{array}$ & $\begin{array}{l}\text { Perda de lo- } \\
\text { cais de grande } \\
\text { beleza cênica } \\
\text { Alteração no } \\
\text { modo de vida } \\
\text { dos atingidos } \\
\text { Perda de biodi- } \\
\text { versidade } \\
\text { Dependência/ } \\
\text { Destinação da } \\
\text { Compensação } \\
\text { Financeira } \\
\text { Perda de terras } \\
\text { produtivas }\end{array}$ & $\begin{array}{l}\text { Tardia } \\
\text { Conflituosa } \\
\text { Pouco cola- } \\
\text { borativa } \\
\text { Demandas } \\
\text { públicas } \\
\text { x licencia- } \\
\text { mento } \\
\text { Comu- } \\
\text { nicação } \\
\text { insuficiente }\end{array}$ \\
\hline $\begin{array}{l}\text { ONG/ } \\
\text { Movi- } \\
\text { mentos } \\
\text { Sociais/ } \\
\text { Ativistas }\end{array}$ & $\begin{array}{l}\text { Impactos x } \\
\text { Poluição } \\
\text { Existência de } \\
\text { lobbies }\end{array}$ & $\begin{array}{l}\text { Renovável } \\
\text { (mas deve- } \\
\text { se conside- } \\
\text { rar o tempo } \\
\text { de vida da } \\
\text { barragem) } \\
\text { Não é limpa } \\
\text { Não é sus- } \\
\text { tentável }\end{array}$ & $\begin{array}{l}\text { Análise de } \\
\text { impactos sinér- } \\
\text { gicos } \\
\text { Reforma política } \\
\text { Atualização do } \\
\text { arcabouço legal }\end{array}$ & $\begin{array}{l}\text { Geração de } \\
\text { energia } \\
\text { Geração de } \\
\text { renda } \\
\text { Evita emissão } \\
\text { de GEE }\end{array}$ & $\begin{array}{l}\text { Alteração no } \\
\text { modo de vida } \\
\text { dos atingidos } \\
\text { Perda de biodi- } \\
\text { versidade } \\
\text { Urbanização } \\
\text { repentina }\end{array}$ & $\begin{array}{l}\text { Questões } \\
\text { complexas } \\
\text { para público } \\
\text { leigo } \\
\text { Objeções } \\
\text { não consi- } \\
\text { deradas } \\
\text { Ausência de } \\
\text { arcabouço } \\
\text { legal } \\
\text { Projetos } \\
\text { apresenta- } \\
\text { dos como } \\
\text { "Fatos Con- } \\
\text { sumados" }\end{array}$ \\
\hline $\begin{array}{l}\text { Advoga- } \\
\text { dos/ } \\
\text { Promo- } \\
\text { tores de } \\
\text { Justiça }\end{array}$ & $\begin{array}{l}\text { Dimensão do } \\
\text { empreendi- } \\
\text { mento } \\
\text { Conflito de } \\
\text { interesses } \\
\text { Comunicação } \\
\text { ineficiente } \\
\text { Dissociação } \\
\text { entre política } \\
\text { energética e } \\
\text { ambiental }\end{array}$ & $\begin{array}{l}\text { Limpa } \\
\text { Renovável } \\
\text { Sustentável }\end{array}$ & $\begin{array}{l}\text { Transparência } \\
\text { Comunicação } \\
\text { Audiência } \\
\text { Pública em novo } \\
\text { formato } \\
\text { Atendimento } \\
\text { das Resoluções } \\
\text { Conama 1/86 e } \\
237 / 97\end{array}$ & $\begin{array}{l}\text { Geração de } \\
\text { energia } \\
\text { Geração de } \\
\text { renda } \\
\text { Evita emissão } \\
\text { de GEE } \\
\text { Perenidade } \\
\text { Usos múltiplos } \\
\text { Turismo }\end{array}$ & $\begin{array}{l}\text { Alterações } \\
\text { hidrológicas } \\
\text { Perda de biodi- } \\
\text { versidade } \\
\text { Poluição da } \\
\text { água - não } \\
\text { supressão da } \\
\text { vegetação } \\
\text { inundada } \\
\text { Urbanização } \\
\text { repentina } \\
\text { Enfermidades } \\
\text { endêmicas } \\
\text { Perda de terras } \\
\text { produtivas }\end{array}$ & $\begin{array}{l}\text { Passível de } \\
\text { manobras } \\
\text { Questões } \\
\text { complexas } \\
\text { para público } \\
\text { leigo } \\
\text { Falta de } \\
\text { compro- } \\
\text { misso }\end{array}$ \\
\hline $\begin{array}{l}\text { Consulto- } \\
\text { rias/ } \\
\text { EIA-Rima }\end{array}$ & $\begin{array}{l}\text { Magnitude } \\
\text { dos impactos } \\
\text { Interferência } \\
\text { de entidades } \\
\text { contrárias } \\
\text { Publicação } \\
\text { de infor- } \\
\text { mações con- } \\
\text { traditórias }\end{array}$ & $\begin{array}{l}\text { Limpa } \\
\text { Renovável } \\
\text { Não informa- } \\
\text { do sobre ser } \\
\text { sustentável }\end{array}$ & $\begin{array}{l}\text { TR próprio para } \\
\text { cada projeto }\end{array}$ & $\begin{array}{l}\text { Geração de } \\
\text { renda } \\
\text { Aumento da } \\
\text { arrecadação } \\
\text { municipal }\end{array}$ & $\begin{array}{l}\text { Alteração no } \\
\text { modo de vida } \\
\text { dos atingidos } \\
\text { Perda de biodi- } \\
\text { versidade } \\
\text { Interferência } \\
\text { sobre sedes } \\
\text { urbanas }\end{array}$ & Conflituosa \\
\hline
\end{tabular}




\begin{tabular}{|c|c|c|c|c|c|c|}
\hline $\begin{array}{l}\text { Empreen } \\
\text { dedor/ } \\
\text { Conces- } \\
\text { sionárias }\end{array}$ & $\begin{array}{l}\text { Magnitude } \\
\text { dos } \\
\text { impactos } \\
\text { Olhos para o } \\
\text { negativo }\end{array}$ & $\begin{array}{l}\text { Controvér- } \\
\text { sias sobre } \\
\text { ser limpa e } \\
\text { renovável } \\
\text { Sustentável }\end{array}$ & $\begin{array}{l}\text { Audiência } \\
\text { Pública em novo } \\
\text { formato } \\
\text { Atenção para a } \\
\text { realidade e as } \\
\text { necessidades } \\
\text { locais }\end{array}$ & $\begin{array}{l}\text { Geração de } \\
\text { renda } \\
\text { Aumento da } \\
\text { arrecadação } \\
\text { municipal } \\
\text { Fortalecimento } \\
\text { do comércio } \\
\text { Melhorias } \\
\text { nos sistemas } \\
\text { de saúde, } \\
\text { educação e } \\
\text { segurança } \\
\text { Turismo }\end{array}$ & $\begin{array}{l}\text { Alteração no } \\
\text { modo de vida } \\
\text { dos atingidos } \\
\text { Aumento das } \\
\text { manifestações } \\
\text { populares } \\
\text { Aumento da } \\
\text { criminalidade }\end{array}$ & $\begin{array}{l}\text { Olhar para a } \\
\text { realidade da } \\
\text { população } \\
\text { atingida } \\
\text { Ausência de } \\
\text { regras }\end{array}$ \\
\hline Biólogos & $\begin{array}{l}\text { Magnitude } \\
\text { dos } \\
\text { impactos } \\
\text { Parcialidade } \\
\text { Deficiência } \\
\text { institucional } \\
\text { Olhos para o } \\
\text { negativo }\end{array}$ & $\begin{array}{l}\text { Respostas } \\
\text { divergentes } \\
\text { sobre o tema }\end{array}$ & $\begin{array}{l}\text { Estudos mais } \\
\text { aprofundados } \\
\text { com dados } \\
\text { primários } \\
\text { Reforma política } \\
\text { Redução da } \\
\text { participação do } \\
\text { empreendedor } \\
\text { no EIA }\end{array}$ & $\begin{array}{l}\text { Geração de } \\
\text { energia } \\
\text { Geração de } \\
\text { renda } \\
\text { Turismo }\end{array}$ & $\begin{array}{l}\text { Perda de lo- } \\
\text { cais de grande } \\
\text { beleza cênica } \\
\text { Perda de biodi- } \\
\text { versidade } \\
\text { Interferência } \\
\text { na migração } \\
\text { e reprodução } \\
\text { de espécies } \\
\text { aquáticas }\end{array}$ & $\begin{array}{l}\text { Comu- } \\
\text { nicação } \\
\text { insuficiente } \\
\text { Questões } \\
\text { complexas } \\
\text { para público } \\
\text { leigo } \\
\text { Conflito de } \\
\text { interesses }\end{array}$ \\
\hline $\begin{array}{l}\text { Governo } \\
\text { Licen- } \\
\text { ciadores } \\
\text { Setor } \\
\text { Elétrico } \\
\text { Infraestru- } \\
\text { tura } \\
\text { Financia- } \\
\text { mento } \\
\text { Locais }\end{array}$ & $\begin{array}{l}\text { Magnitude } \\
\text { dos } \\
\text { impactos } \\
\text { Conflito de } \\
\text { interesses } \\
\text { Participação } \\
\text { pública insufi- } \\
\text { ciente } \\
\text { Estudos } \\
\text { superfi- } \\
\text { ciais sobre } \\
\text { determinados } \\
\text { temas } \\
\text { Existência de } \\
\text { lobbies } \\
\text { Oposição } \\
\text { ideológica } \\
\text { Comunicação } \\
\text { ineficiente } \\
\text { Exigências } \\
\text { desvincu- } \\
\text { ladas do } \\
\text { projeto } \\
\text { Interesses } \\
\text { econômicos } \\
\text { sobre os } \\
\text { demais }\end{array}$ & $\begin{array}{l}\text { Limpa } \\
\text { Renovável } \\
\text { Sustentável }\end{array}$ & $\begin{array}{l}\text { Desburo } \\
\text { cratização da } \\
\text { legislação } \\
\text { Planejamento de } \\
\text { ações interinsti- } \\
\text { tucionais } \\
\text { Alinhamento } \\
\text { conceitual dos } \\
\text { estudos exigidos } \\
\text { Definição de } \\
\text { regras, escopo e } \\
\text { responsabi- } \\
\text { lidades para a } \\
\text { elaboração dos } \\
\text { estudos } \\
\text { Apresentação } \\
\text { de estudos que } \\
\text { atendam ao TR } \\
\text { Análise padrão } \\
\text { para os estudos } \\
\text { Maio enfoque } \\
\text { na população } \\
\text { diretamente } \\
\text { afetada } \\
\text { Atenção igual } \\
\text { aos aspectos } \\
\text { econômicos, } \\
\text { sociais e ambi- } \\
\text { entais }\end{array}$ & $\begin{array}{l}\text { Geração de } \\
\text { energia } \\
\text { Geração de } \\
\text { renda } \\
\text { Aumento da } \\
\text { arrecadação } \\
\text { municipal } \\
\text { Regulari- } \\
\text { zação de } \\
\text { vazões e con- } \\
\text { trole de cheias } \\
\text { Limpa e reno- } \\
\text { vável } \\
\text { "Armazena- } \\
\text { mento" de } \\
\text { energia nos } \\
\text { reserva- } \\
\text { tórios } \\
\text { Desenvolvi- } \\
\text { mento regional } \\
\text { Presença do } \\
\text { Estado nas } \\
\text { regiões }\end{array}$ & $\begin{array}{l}\text { Alteração no } \\
\text { modo de vida } \\
\text { dos atingidos } \\
\text { Perda de biodi- } \\
\text { versidade } \\
\text { Urbanização } \\
\text { repentina } \\
\text { Dependência/ } \\
\text { Destinação da } \\
\text { Compensação } \\
\text { Financeira } \\
\text { Interferência } \\
\text { na migração } \\
\text { e reprodução } \\
\text { de espécies } \\
\text { aquáticas } \\
\text { Perda de } \\
\text { patrimônio } \\
\text { histórico e } \\
\text { arqueológico } \\
\text { Sazonalidade } \\
\text { Morosidade } \\
\text { Burocracia }\end{array}$ & $\begin{array}{l}\text { Conflito de } \\
\text { interesses } \\
\text { Tomada } \\
\text { de decisão } \\
\text { exclusiva } \\
\text { do poder } \\
\text { público } \\
\text { Desconhe- } \\
\text { cimento da } \\
\text { finali- } \\
\text { dade das } \\
\text { Audiências } \\
\text { Públicas } \\
\text { Limitada } \\
\text { Ausência de } \\
\text { regras } \\
\text { Comu- } \\
\text { nicação } \\
\text { insuficiente } \\
\text { Falta de } \\
\text { visão macro } \\
\text { do projeto }\end{array}$ \\
\hline
\end{tabular}


Quadro l - Síntese dos resultados obtidos com os questionários aplicados com os atores envolvidos no processo de licenciamento ambiental no Brasil

[continuação]

\begin{tabular}{|c|c|c|c|c|c|}
\hline GRUPOS & $\begin{array}{l}\text { ASPECTOS } \\
\text { POSITIVOS DO } \\
\text { LICENCIA- } \\
\text { MENTO }\end{array}$ & $\begin{array}{c}\text { LACUNAS } \\
\text { DO } \\
\text { LICENCIAMENTO }\end{array}$ & $\begin{array}{l}\text { O LICENCIA- } \\
\text { MENTO AM- } \\
\text { BIENTAL HOJE }\end{array}$ & $\begin{array}{c}\text { O SETOR } \\
\text { ELÉTRICO E } \\
\text { A SUSTEN- } \\
\text { TABILIDADE }\end{array}$ & $\begin{array}{l}\text { DESAFIOS } \\
\text { FUTUROS }\end{array}$ \\
\hline $\begin{array}{l}\text { Acadêmicos/ } \\
\text { Especialistas }\end{array}$ & $\begin{array}{l}\text { Maior transparên- } \\
\text { cia ao processo } \\
\text { decisório } \\
\text { Redução de im- } \\
\text { pactos ambientais } \\
\text { Identificação e } \\
\text { avaliação de } \\
\text { impactos } \\
\text { Minimização e } \\
\text { compensação de } \\
\text { impactos } \\
\text { Descentralização } \\
\text { das competências }\end{array}$ & $\begin{array}{l}\text { Participação social } \\
\text { insuficiente } \\
\text { Não há análise de } \\
\text { alternativas } \\
\text { Pouca importância } \\
\text { à etapa de pós } \\
\text { operação } \\
\text { Definição de alter- } \\
\text { nativas locacionais } \\
\text { e tecnológicas an- } \\
\text { tes da identificação } \\
\text { dos impactos } \\
\text { Omissões no EIA } \\
\text { Demorado } \\
\text { Exigências inexe- } \\
\text { quíveis para o } \\
\text { empreendedor }\end{array}$ & $\begin{array}{l}\text { Conflituoso } \\
\text { Moroso } \\
\text { Burocrático }\end{array}$ & $\begin{array}{l}\text { Crescimento } \\
\text { econômico é } \\
\text { preponderante }\end{array}$ & $\begin{array}{l}\text { Negociação de } \\
\text { trade-offs } \\
\text { Avaliação da } \\
\text { necessidade } \\
\text { de expansão }\end{array}$ \\
\hline $\begin{array}{l}\text { ONG/ } \\
\text { Movimentos } \\
\text { Sociais/ } \\
\text { Ativistas }\end{array}$ & $\begin{array}{l}\text { Estudos ambi- } \\
\text { entais e sociais } \\
\text { prévios } \\
\text { Imposição de } \\
\text { condicionantes } \\
\text { Participação social } \\
\text { Revisibilidade } \\
\text { judicial } \\
\text { Regulação do } \\
\text { conflito } \\
\text { Realização do EIA }\end{array}$ & $\begin{array}{l}\text { Submissão de } \\
\text { parecer técnico ao } \\
\text { julgamento político } \\
\text { Não considera } \\
\text { objeç̃̃es feitas em } \\
\text { Audiências Públicas } \\
\text { e ao longo do } \\
\text { processo } \\
\text { Não é respeitado } \\
\text { pelo governo } \\
\text { Politizado } \\
\text { Antidemórático } \\
\text { Não há análises } \\
\text { integradas }\end{array}$ & Ineficiente & $\begin{array}{l}\text { Crescimento } \\
\text { econômico é } \\
\text { preponderante }\end{array}$ & $\begin{array}{l}\text { Respeito à } \\
\text { diversidade } \\
\text { sociocultural } \\
\text { e da liberdade } \\
\text { dos povos } \\
\text { Alterações } \\
\text { no arcabouço } \\
\text { legal }\end{array}$ \\
\hline $\begin{array}{l}\text { Advogados/ } \\
\text { Promotores } \\
\text { de Justiça }\end{array}$ & $\begin{array}{l}\text { Compensação } \\
\text { Ambiental } \\
\text { Redução de im- } \\
\text { pactos ambientais } \\
\text { Melhorias na } \\
\text { infraestrutura } \\
\text { Definição de } \\
\text { parâmetros } \\
\text { ambientais } \\
\text { Aparato legal } \\
\text { Descentralização } \\
\text { das competências } \\
\text { Participação social } \\
\text { Reconhecimento } \\
\text { do dano }\end{array}$ & $\begin{array}{l}\text { Falta de transpa- } \\
\text { rência } \\
\text { Carência de legis- } \\
\text { lação ambiental } \\
\text { Prazos longos } \\
\text { para a análise dos } \\
\text { estudos } \\
\text { Fiscalização insufi- } \\
\text { ciente } \\
\text { Ausência de } \\
\text { normas para a ela- } \\
\text { boração do Plano } \\
\text { Básico Ambiental }\end{array}$ & $\begin{array}{l}\text { Moroso } \\
\text { Burocrático }\end{array}$ & $\begin{array}{l}\text { Crescimento } \\
\text { econômico é } \\
\text { preponderante }\end{array}$ & $\begin{array}{l}\text { Inclusão da } \\
\text { população } \\
\text { diretamente } \\
\text { atingida no } \\
\text { rateio dos } \\
\text { benefícios } \\
\text { Avanço nas } \\
\text { discussões } \\
\text { sobre licen- } \\
\text { ciamento e a } \\
\text { sustenta- } \\
\text { bilidade do } \\
\text { crescimento } \\
\text { econômico }\end{array}$ \\
\hline
\end{tabular}




\begin{tabular}{|c|c|c|c|c|c|}
\hline $\begin{array}{l}\text { Consultorias/ } \\
\text { EIA-Rima }\end{array}$ & $\begin{array}{l}\text { Participação social } \\
\text { Identificação e } \\
\text { avaliação de } \\
\text { impactos }\end{array}$ & $\begin{array}{l}\text { Termos de Referên- } \\
\text { cia complexos } \\
\text { Prazos longos } \\
\text { para a análise dos } \\
\text { estudos } \\
\text { Exigências inexe- } \\
\text { quíveis para o } \\
\text { empreendedor }\end{array}$ & $\begin{array}{l}\text { Extremamente } \\
\text { caro }\end{array}$ & $\begin{array}{l}\text { Crescimento } \\
\text { econômico é } \\
\text { preponderante }\end{array}$ & $\begin{array}{l}\text { Atender a } \\
\text { demanda } \\
\text { considerando } \\
\text { a inserção das } \\
\text { variáveis } \\
\text { ambientais }\end{array}$ \\
\hline $\begin{array}{l}\text { Empreen- } \\
\text { dedor/ } \\
\text { Conces- } \\
\text { sionárias }\end{array}$ & $\begin{array}{l}\text { Realização do EIA } \\
\text { Participação social } \\
\text { Descentralização } \\
\text { das competências }\end{array}$ & $\begin{array}{l}\text { Não operacional } \\
\text { Falta de inves- } \\
\text { timentos na } \\
\text { capacitação dos } \\
\text { servidores públicos } \\
\text { Fiscalização } \\
\text { insuficiente }\end{array}$ & $\begin{array}{l}\text { Passível de } \\
\text { corrupção }\end{array}$ & $\begin{array}{l}\text { Crescimento } \\
\text { econômico é } \\
\text { preponderante }\end{array}$ & $\begin{array}{l}\text { Planejamento } \\
\text { integrado }\end{array}$ \\
\hline Biólogos & $\begin{array}{l}\text { Estudos ambi- } \\
\text { entais e sociais } \\
\text { prévios } \\
\text { Participação social } \\
\text { Compensação } \\
\text { Ambiental } \\
\text { Aparato legal }\end{array}$ & $\begin{array}{l}\text { Escolha de empre- } \\
\text { sas por licitação } \\
\text { Tomadores de } \\
\text { decisão com outros } \\
\text { interesses } \\
\text { Fiscalização } \\
\text { insuficiente } \\
\text { Elaboração de } \\
\text { estudos superficiais } \\
\text { Politizado }\end{array}$ & $\begin{array}{l}\text { Moroso } \\
\text { Burocrático }\end{array}$ & $\begin{array}{l}\text { Crescimento } \\
\text { econômico é } \\
\text { preponderante }\end{array}$ & $\begin{array}{l}\text { Licenciamento } \\
\text { tendo como } \\
\text { base o } \\
\text { desenvolvimen- } \\
\text { to sustentável }\end{array}$ \\
\hline $\begin{array}{l}\text { Governo } \\
\text { Licen- } \\
\text { ciadores } \\
\text { Setor } \\
\text { Elétrico } \\
\text { Infraestru- } \\
\text { tura } \\
\text { Financia- } \\
\text { mento } \\
\text { Locais }\end{array}$ & $\begin{array}{l}\text { Estudos ambi- } \\
\text { entais e sociais } \\
\text { prévios } \\
3 \text { fases (prévia, } \\
\text { instalação e } \\
\text { operação) } \\
\text { Participação social } \\
\text { Maior transparên- } \\
\text { cia ao processo } \\
\text { decisório } \\
\text { Realização do EIA } \\
\text { Legitimidade da } \\
\text { questão ambiental } \\
\text { e social } \\
\text { Amadurecimento } \\
\text { do órgão } \\
\text { ambiental }\end{array}$ & $\begin{array}{l}\text { Exclusividade do } \\
\text { órgão licenciador } \\
\text { na tomada de } \\
\text { decisão } \\
\text { Participação social } \\
\text { insuficiente } \\
\text { Judicialização } \\
\text { excessiva } \\
\text { Políticas públicas x } \\
\text { licenciamento } \\
\text { Morosidade de } \\
\text { alguns processos } \\
\text { Participação } \\
\text { institucional tardia } \\
\text { Indefinição do esco- } \\
\text { po e respon- } \\
\text { sabilidades sobre a } \\
\text { elaboração do EIA }\end{array}$ & $\begin{array}{l}\text { Moroso } \\
\text { Burocrático }\end{array}$ & $\begin{array}{l}\text { Crescimento } \\
\text { econômico é } \\
\text { preponderante }\end{array}$ & $\begin{array}{l}\text { Planejamento } \\
\text { integrado } \\
\text { Participação } \\
\text { social } \\
\text { Garantir } \\
\text { condição } \\
\text { decisória }\end{array}$ \\
\hline
\end{tabular}


Parte dos entrevistados considerou o processo de licenciamento politizado. Independente da AIA, a possibilidade de mitigação e compensação é suficiente para a liberação das licenças e esse fato é reforçado por interesses políticos. A sobreposição de interesses políticos em relação a outros desconfigura o processo de licenciamento na medida em que se perde o sentido de sua finalidade. Para Zhouri e Oliveira (2007) as forças desiguais sustentadas por diferentes posições perpetuam políticas socialmente injustas e ambientalmente insustentáveis, prejudicando o processo de licenciamento ambiental.

Entre os impactos positivos mencionados pelos entrevistados, o mais citado foi a geração de energia elétrica. A geração de renda, decorrente do aumento do número de empregos, também foi lembrada como impacto positivo. O aumento da arrecadação municipal pelo recebimento da Compensação Financeira também foi citado como impacto positivo, tendo em vista as possibilidades de desenvolvimento que podem surgir para a região que integra a área de influência do empreendimento. A baixa emissão de GEE associada ao uso da hidreletricidade também foi apontada como impacto positivo pela maioria dos entrevistados.

Com relação aos impactos negativos, o mais citado pelos entrevistados foi a alteração no modo de vida da população diretamente atingida. Outro impacto negativo citado foi a urbanização excessiva. $\mathrm{O}$ aumento da arrecadação municipal pelo recebimento da Compensação Financeira também foi citado como impacto negativo, pois a dependência de um município pelos recursos oriundos dessa fonte pode ser prejudicial para o desenvolvimento local.

Apesar de positiva e representar um avanço no marco legal ambiental, na interpretação dos entrevistados, a participação pública durante o processo de licenciamento ambiental é limitada e pouco colaborativa. Tal ponto elucida a necessidade premente que é a revisão do arcabouço legal sobre esse tema, especialmente por ser esse o mecanismo previsto em lei para viabilizar a participação social e a resolução dos conflitos no âmbito do licenciamento. O que se observa atualmente é que, ao contrário do que se espera, as Audiências Públicas são palco para a realização de confrontos e embates entre públicos com interesses distintos, estando longe de cumprir os seus reais objetivos.

Para a maioria dos entrevistados, a possibilidade de participação social constitui em avanço do processo de licenciamento ambiental, apesar dos problemas verificados no item anterior. A descentralização do processo mediante a definição das competências compartilhadas entre União, estados e municípios e a maior transparência durante o processo também foram lembradas.

Questões de ordem técnica também foram consideradas avanços, entre elas, (i) a elaboração de estudos ambientais prévios, inclusive os estudos de inventário e o EIA-Rima e, consequentemente, a redução ou a não ocorrência de certos impactos negativos; (ii) a possibilidade de mitigação e compensação de impactos ambientais negativos; (iii) a imposição de condicionantes à emissão das 
licenças; (iv) a possibilidade de Compensação Ambiental, conforme artigo 36 da lei SNUC; e (v) a definição de parâmetros ambientais para monitoramento. A existência de um arcabouço legal e institucional também foi citada como avanço.

Mesmo com os avanços identificados, existem lacunas. Uma delas, mencionada por representantes dos órgãos licenciadores, merece destaque. O processo de tomada de decisão sobre a viabilidade de um empreendimento é conduzido tão somente pelos órgãos licenciadores. Outras lacunas:

- Participação pública insipiente;

- Ausência de monitoramento e fiscalização após a operação do empreendimento;

- Julgamento político dos pareceres técnicos;

- Elaboração de estudos superficiais;

- Processo demorado;

- Exigências inexequíveis em virtude da ausência de políticas públicas na maioria das localidades; e,

- Judicialização excessiva.

O processo de licenciamento ambiental brasileiro foi considerado moroso e burocrático pela maioria dos entrevistados. Em razão da situação verificada, o relatório do Banco Mundial de 2008 destaca que "dentro do próprio governo, o licenciamento ambiental em si é considerado moroso e o processo burocrático", provavelmente por não conseguir acompanhar os passos do setor elétrico, especialmente, no que diz respeito à expansão energética. Todavia, "não é o custo de mitigação o obstáculo e sim a falta de visão holística dentro do próprio governo, de como melhor gerir a questão ambiental e as necessidades de crescimento" (BIRD, 2008).

O crescimento econômico, a conservação ambiental e o envolvimento social são fatores que interferem no desenvolvimento do setor elétrico. Para todos os entrevistados, o crescimento econômico é preponderante, mas não exclui a importância da conservação ambiental e do envolvimento social, apesar de atualmente se apresentarem em segundo plano. Finalmente, os entrevistados foram questionados sobre os possíveis desafios que se têm pela frente para aprimorar o processo de licenciamento ambiental tornando-o mais eficiente.

Para os entrevistados, é necessária a adoção de algumas ações, entre elas, alterações no arcabouço legal, avaliação da necessidade de expansão, respeito à diversidade sociocultural e da liberdade das comunidades atingidas, inclusão da população diretamente atingida no rateio dos benefícios, avanço nas discussões sobre licenciamento e a sustentabilidade do crescimento econômico, atendimento à demanda considerando a inserção das variáveis ambientais, planejamento integrado, participação social e garantia condição decisória. 


\section{Considerações finais}

Os resultados obtidos com a aplicação dos questionários e sintetizados no Quadro 1 demonstram a diversidade de opiniões e interpretações sobre a hidroeletricidade e o processo de AIA e de licenciamento ambiental. A reunião de informações tão diversas, dessa natureza, constitui-se em importante ferramenta de planejamento e participação que pode orientar e direcionar ações futuras, benéficas para a sociedade como um todo.

Em geral, as informações obtidas com a aplicação dos questionários confirmam que os pontos de vista são influenciados pelos papeis e interesses de cada grupo de entrevistados. Em alguns casos foi possível observar opiniões distintas sobre um tema num mesmo grupo de indivíduos entrevistados.

Esses grupos estavam representados por acadêmicos, especialistas, biólogos, advogados e promotores de justiça. As opiniões desses entrevistados nem sempre foram as mesmas. Uma característica peculiar desses grupos é a abrangência de sua atuação cuja principal finalidade está em orientar toda a sociedade, quer pelo aprofundamento teórico sobre as questões biofísicas e sociais tratadas pelos acadêmicos, quer pelo suporte jurídico, especialmente nas situações de conflito.

Os demais grupos entrevistados apresentaram opiniões semelhantes sobre os temas tratados, reforçando a tese de que a abrangência de atuação influencia no modo de pensar e agir dos indivíduos. Esses grupos foram representados por ONG, Movimentos Sociais, ativistas, empresas de consultoria que elaboram EIA-Rima, concessionárias de energia elétrica e órgãos governamentais em todas as suas esferas.

O papel das ONG, dos Movimentos Sociais e ativistas, no âmbito do licenciamento, relaciona-se diretamente a garantir a conservação da biodiversidade e a manutenção do modo de vida das comunidades diretamente atingidas pela instalação do empreendimento. As empresas de consultoria são responsáveis pela elaboração dos estudos ambientais que definem a viabilidade de um empreendimento. $\mathrm{O}$ fato de esses estudos serem contratados pelo empreendedor restringe as possibilidades de indeferimento do processo pela inviabilidade ambiental do empreendimento. A possibilidade de mitigação ou compensação dos impactos negativos também restringe o indeferimento. As concessionárias de energia têm por objetivo gerar energia, dessa forma as opiniões se convergem.

Os órgãos governamentais foram representados pelos setores: elétrico, de financiamento, de infraestrutura, além de órgãos licenciadores e locais. De certa forma, todos creem que o crescimento econômico é importante para o desenvolvimento do país e que as questões ambientais e sociais são tratadas no âmbito do EIA-Rima, e que os impactos gerados podem ser minimizados ou compensados, o que não impede o andamento do processo. Justificam-se pelos impactos positivos da obra, entre eles a geração de renda e de energia elétrica.

Os órgãos licenciadores são os responsáveis pela tomada de decisão sobre a viabilidade de um empreendimento. Observa-se que os interesses políticos 
se sobrepõem aos demais interesses prejudicando a AIA e o licenciamento ambiental como um todo. Apesar dos pareceres técnicos contrários, que sempre solicitam complementações, quando não a reelaboração dos estudos. Ademais, a instalação de UHE envolve interesses coletivos, de toda a sociedade, o que denota a importância do processo decisório mais abrangente e menos desigual.

Certamente, passados pouco mais de trinta anos do desenvolvimento de normativas legais relacionadas ao licenciamento ambiental brasileiro, é possível observar avanços no tratamento das questões ambientais e sociais intrínsecas a instalação de projetos que causam impactos ambientais significativos. Mas ainda é cedo para afirmar que as ações desenvolvidas compactuam do que hoje pode ser definido como sustentável. A divergência de opiniões, pautadas por interesses e objetivos distintos, é, de um lado, interessante no instante em que enriquecem o debate. Todavia, tal cenário revela a permanência de uma imaturidade social arraigada na existência de priorizações específicas, quando na verdade tais ações deveriam ser conduzidas sob uma visão sistêmica. Os interesses individuais e grupais passam a denominar-se lacunas, especialmente quando a visão do processo é total, abrangente ou sistêmica. Um dos caminhos a sugerir seria aprofundar os estudos almejando-se obter uma visão sistêmica, considerando as especificidades de cada área envolvida.

Nota

l Os órgãos licenciadores que atuam de modo indireto são aqueles que prestam esclarecimentos e emitem seus pareceres mediante a solicitação do órgão licenciador responsável e, também, pela sua atuação específica num determinado tema, por exemplo, arqueologia, questões indígenas, unidades de conservação, entre outros.

\section{Referências}

ACSELRAD, $\mathrm{H}$. As práticas espaciais e o campo dos conflitos ambientais. In: (Coord.) Conflitos ambientais no Brasil. Rio de Janeiro: Fundação Heinrich Böll; Relume Dumará, 2004.

AGRA FILHO, S. S. Conflitos ambientais e os instrumentos da política nacional do meio ambiente. eGesta, v.4, n.2, p.127-40, abr.-jun. 2008,

ALONSO, A.; COSTA, V. Por uma sociologia dos conflitos ambientais no Brasil. Buenos Aires: Consejo Latinoamericano de Ciencias Sociales - Clacso, 2002.

BANCO MUNDIAL - BIRD. Licenciamento Ambiental de Empreendimentos Hidrelétricos no Brasil: uma contribuição para o debate. Banco Mundial. Volume II. Relatório Principal, 2008.

BRITO, D. M. C. et al. Conflitos socioambientais no século XXI. PRACS: Revista de Humanidades do Curso de Ciências Sociais da UNIFAP. Macapá, n.4, p.51-8, dez. 2011.

DEUTSCH, M. The resolution of conflict: constructive and destructive processes. New Haven; London: Yale University Press, 1973. 
DEUTSCH, M. The resolution of conflict: constructive and destructive processes In: AZEVEDO, A. G. (Org.) Estudos em arbitragem, mediação e negociação. Brasília: Grupos de Pesquisa, 2003.

GALVANESE, C. S. Dilemas do planejamento e as instituições do desenvolvimento sustentável. Estudo sobre as barragens e a questão regional do Vale do Ribeira. 2009. Dissertação (Mestrado) - Universidade Federal do ABC. Santo André, 2009.

PIMENTEL, T. T. B. C. O enfrentamento político dos conflitos socioambientais decorrentes da implantação de usinas hidrelétricas. 2012. Dissertação (Mestrado) - Pontifícia Universidade Católica. Brasília, 2012.

SWAIN, A.; CHEE, A. M. Political structure and dam conflicts: comparing cases in Southeast Asia. In: Water \& politics: understanding the role of politics in water management. Marseille: WWC, 2004.

VAINER, C. B. Recursos hidráulicos: questões sociais e ambientais. Revista Estudos Avançados, São Paulo, v.21, n.59, p.119-37, 2007.

ZHOURI, A.; OLIVEIRA, R. Desenvolvimento, conflitos sociais e violência no Brasil Rural: O caso das usinas hidrelétricas. Revista Ambiente \& Sociedade, Campinas, v.X, n.2, p.119-37, 2007.

RESUMO - A hidreletricidade desempenha papel estratégico na política energética brasileira e mundial. Apesar de vantagens como custo competitivo e caráter renovável e pouco poluente, os impactos negativos comprometem sua expansão. A dimensão do empreendimento, dos impactos e do número de atores envolvidos se traduz em conflitos cada vez mais frequentes e de difícil equacionamento. $\mathrm{O}$ artigo apresenta os pontos de vista de atores envolvidos no processo de licenciamento ambiental hidrelétrico brasileiro, colhidos mediante aplicação de questionários. Conclui-se que, mesmo com os avanços, ainda há uma imaturidade social destacada por uma visão segmentada, onde prevalecem interesses individuais e grupais, o que não descarta que uma visão sistêmica e equânime seja estabelecida.

PALAVRAS-CHAVE: Hidreletricidade, Licenciamento, Impactos, Conflitos, Interesses.

ABSTRACT - Hydropower plays a strategic role in energy policy in Brazil and worldwide. Despite advantages such as cost competitive and low-polluting and renewable nature, negative impacts undertake its expansion. The size of the development, the impacts and the number of actors involved translates into conflicts increasingly frequent and difficult equation. The article presents the views of stakeholders in the process of environmental licensing Brazilian hydroelectric, collected through questionnaires. We conclude that, 
even with the advances, there is still a social immaturity highlighted by a segmented view, where individual and group interests prevail, which does not rule out that a systemic and equitable be established.

KErWORDS: Hydroelectricity, Licensing, Impacts, Conflicts, Interests.

Priscilla Melleiro Piagentini é doutora em Energia pela Universidade Federal do ABC. @ - pmpiagentini@uol.com.br

Roseli Frederigi Benassi é professora do Centro de Engenharia, Modelagem e Ciências Sociais Aplicadas da Universidade Federal do ABC. @ - roseli.benassi@ufabc.edu.br

Cláudio Luis Camargo Penteado é professor do Centro de Engenharia, Modelagem e Ciências Sociais Aplicadas da Universidade Federal do ABC.

@ - claudio.penteado@ufabc.edu.br

Recebido em 14.8.2013 e aceito em 7.12.2013.

I, II e III Centro de Engenharia, Modelagem e Ciências Sociais, Universidade Federal do ABC, Santo André/SP, Brasil. 
